\title{
EDITORIAL
}

\section{The Long Loneliness of Primary Care}

\author{
Timotby P. Daaleman, DO, MPH \\ Department of Family Medicine, University of North Carolina at Chapel Hill, Chapel Hill, North Carolina
}

Ann Fam Med 2018;16:388-389. https://doi.org/10.1370/afm.2301

I $\mathrm{n}$ recent years there has been heightened interest in the linkages between loneliness, social isolation, and health. A highly cited meta-analysis determined that social isolation, loneliness, and living alone increased the risk of premature death by an order of magnitude that was comparable to the well-recognized risk factors of smoking and obesity. ${ }^{1}$ In addition, a data analysis from the Health and Retirement Study reported that loneliness was significantly associated with increased physician visits, but not hospitalizations, in community-dwelling older adults. ${ }^{2}$

It's unclear if a critical mass of research ${ }^{1,2}$ or dissemination of this work in the media ${ }^{3}$ has led to a tipping point, as evidenced by the appointment of a Minister of Loneliness in the United Kingdom. ${ }^{3}$

Prevalence estimates of loneliness range from approximately $10 \%$ in the general population ${ }^{5}$ to onethird to one-half of older adults. ${ }^{6}$ Existing research has focused on examining the effects of loneliness and social isolation on health outcomes and health care utilization.

Loneliness and social isolation are conceptually related and are often studied in tandem ${ }^{1}$; loneliness is usually defined as a subjectively painful experience due to the absence of social contact while social isolation refers to the objective lack of social contact. ${ }^{1,5}$

This issue of the Annals includes a practice-based study from Aoki and colleagues, and a reflection essay by Frey, contributions that provide signposts to an emerging cartography of loneliness, social isolation, and health. ${ }^{7,8}$ In a population of community-dwelling elderly patients from Japan, social isolation was associated with a less favorable experience of primary care, as measured by an adapted version of the validated

Conflicts of interest: author reports none.

\section{CORRESPONDING AUTHOR}

Timothy P. Daaleman, DO, MPH

Department of Family Medicine

University of North Carolina at Chapel Hill

Campus Box 7595

Chapel Hill, NC 275199-7595

tim_daaleman@med.unc.edu
Primary Care Assessment Tool (PCAT). ${ }^{7}$ Patients who were socially isolated reported a poorer experience of primary care in the areas of longitudinality (ie, continuous, ongoing care), comprehensiveness (ie, availability of wide range of services), and community orientation (ie, concern with health needs of community), when compared with patients who were not isolated. ${ }^{7}$

Social connectedness - the inverse of loneliness and social isolation-has been included with health behaviors, biomarkers, and medical treatment adherence in causal pathways that depict plausible factors influencing morbidity and mortality. ${ }^{9}$ The Aoki study introduces the idea that there may be medical encounter-level factors at play, too. Although social isolation may be lessened by gaining new acquaintances, ameliorating loneliness generally takes longer and can only be eased by forming an intimate connection with someone else. ${ }^{10}$ For patients, this close relationship may include their personal physician. If continuity of care is associated with the improved receipt of preventive services and reduced hospitalizations, ${ }_{1}^{11}$ could the primary care environment and the tenor of continuity visits be mediators of health outcomes in lonely or socially isolated patients? Indeed, generalist physicians report that caring for lonely patients evokes feelings of powerlessness and frustration, which may contribute to less time spent during encounters. ${ }^{12}$

The Frey essay directs attention to the experience of loneliness and isolation in physicians, ${ }^{8}$ a phenomenon that is minimally mentioned in the ongoing conversation on burnout and professional dissatisfaction. ${ }^{8,13}$ There are 3 categories of physician isolation; professional, structural, and social. ${ }^{14}$ Professional isolation is not uncommon in rural practice and can be due to barriers in accessing clinical information and decision support, the varied availability of specialty consultation, and hampered networking with colleagues. ${ }^{14}$ Structural isolation refers to the physical design features of health care settings (eg, examination rooms) that impede communication with team members, and which constrain consultation with colleagues. ${ }^{14}$ Social isolation is described as a form of loneliness and, as noted earlier, is mitigated by establishing meaningful 
connections with others. ${ }^{10}$ Through his reminiscence of the doctors' dining room, Frey illustrates the physical and relational components of safe spaces that facilitate meaningful conversation and relationship-building, important counterweights to structural isolation. ${ }^{8}$ In addition, he offers both empiric and wisdom-based approaches for physicians who may be seeking to remedy their own professional and social isolation. ${ }^{8}$

The activity of developing and maintaining relationships with patients is a core component of primary care, one that gives meaning to the everyday work of generalist physicians. ${ }^{15}$ Sustaining meaningful relationships, however, can be emotionally draining and professionally hazardous, often confronting clinicians with their sense of self as a doctor. ${ }^{15}$ Balint groups ${ }^{16}$ and virtual communities of practice ${ }^{14}$ are a few of the interpersonal and organizational-level strategies that have been used with primary care physicians to address these occupational challenges. Findings from a series of studies on social exclusion and life meaning ${ }^{17}$ provide insight and guidance to future work in this area. First, individuals who were socially excluded were less likely to view their current work as tied to a desired future state. ${ }^{17}$ The second finding was that exclusion lessened self-efficacy, or the perception that an individual had control over their life. ${ }^{17}$ Being socially excluded also reduced one's perceived self-value, or the belief that the individual was a moral being. ${ }^{17}$ And finally, social exclusion diminished one's self-worth in a way caused an individual to see their own abilities and strengths less favorably. ${ }^{17}$ The takeaway from these studies is that when a sense of belonging is threatened-by loneliness or through social isolation-people perceive less meaning in their lives. ${ }^{17}$

The Aoki study and Frey essay provide a primary care perspective that adds new ways of thinking about loneliness, social isolation, and health. For primary care investigators who may be seeking to develop and test interventions for lonely patients, for medical directors looking to adopt programs that can promote social connectedness in the workplace, and for physicians who may be struggling with their own professional isolation, it is our connectedness with others that matters. The social activist Dorothy Day captured this best decades ago when she observed that, "we have all known the long loneliness, and have learned that the only solution comes with community."18

To read or post commentaries in response to this article, see it online at http://www.AnnFamMed.org/content/16/5/388.
Key words: loneliness; social isolation; primary care; patient-physician relationship

Submitted July 25, 2018; accepted August 1, 2018.

\section{References}

1. Holt-Lunstad J, Smith TB, Baker M, Harris T, Stephenson D. Loneliness and social isolation as risk factors for mortality: a metaanalytic review. Perspect Psychol Sci. 2015;10(2):227-237.

2. Gerst-Emerson K, Jayawardhana J. Loneliness as a public health issue: the impact of loneliness on health care utilization among older adults. Am J Public Health. 2015;105(5):1013-1019.

3. Klinenberg E. Is loneliness a health epidemic? New York Times. February 9, 2018:SR8.

4. Gulland A. Sixty seconds on . . loneliness. BMJ. 2018;360:k300.

5. Beutel ME, Klein EM, Brähler $\mathrm{E}$, et al. Loneliness in the general population: prevalence, determinants and relations to mental health. BMC Psychiatry. 2017;17(1):97.

6. Perissinotto CM, Stijacic Cenzer I, Covinsky KE. Loneliness in older persons: a predictor of functional decline and death. Arch Intern Med. 2012;172(14):1078-1083.

7. Aoki T, Yamamoto Y, Ikenoue T, et al. Social isolation and patient experience in older adults. Ann Fam Med. 2018;16(5):393-398.

8. Frey JJ III. Professional loneliness and the loss of the doctors' dining room. Ann Fam Med. 2018;16(5):461-463.

9. Holt-Lunstad J, Smith TB. Loneliness and social isolation as risk factors for CVD: implications for evidence-based patient care and scientific inquiry. Heart. 2016;102(13):987-989.

10. Dickens AP, Richards SH, Greaves CJ, Campbell JL. Interventions targeting social isolation in older people: a systematic review. BMC Public Health. 2011;11:647.

11. Saultz JW, Lochner J. Interpersonal continuity of care and care outcomes: a critical review. Ann Fam Med. 2005;3(2):159-166.

12. van der Zwet J, Koelewijn-van Loon MS, van den Akker M. Lonely patients in general practice: a call for revealing GPs' emotions? A qualitative study. Fam Pract. 2009;26(6):501-509.

13. West CP, Dyrbye LN, Erwin PJ, Shanafelt TD. Interventions to prevent and reduce physician burnout: a systematic review and metaanalysis. Lancet. 2016;388(10057):2272-2281.

14. Barnett S, Jones SC, Bennett S, Iverson D, Bonney A. General practice training and virtual communities of practice - a review of the literature. BMC Fam Pract. 2012;13:87.

15. Fairhurst K, May C. What general practitioners find satisfying in their work: implications for health care system reform. Ann Fam Med. 2006;4(6):500-505.

16. Kjeldmand D, Holmström I. Balint groups as a means to increase job satisfaction and prevent burnout among general practitioners. Ann Fam Med. 2008;6(2):138-145.

17. Stillman TF, Baumeister RF, Lambert NM, Crescioni AW, Dewall CN, Fincham FD. Alone and without purpose: life loses meaning following social exclusion. J Exp Soc Psychol. 2009;45(4):686-694.

18. Day D. The Long Loneliness: The Autobiography of Dorothy Day. San Francisco, CA: Harper \& Row; 1981. 